\title{
Behavioral and Neurochemical Recovery from Partial 6-Hydroxydopamine Lesions of the Substantia Nigra Is Blocked by Daily Treatment with Glutamate Receptor Antagonists MK-801 and CPP
}

\author{
Adriana Emmi, Heshmat Rajabi, and Jane Stewart \\ Center for Studies in Behavioral Neurobiology, Department of Psychology, Concordia University, Montréal, Québec, \\ Canada H3G 1 M8
}

To determine whether glutamate plays a role in the recovery from lesions of the substantia nigra, measures of behavioral functioning and extracellular levels of striatal dopamine (DA) were made after partial unilateral 6-OHDA lesions in adult male rats. In experiments 1 and 2, animals were treated on days 1-8 after lesioning with the noncompetitive NMDA receptor antagonist dizocilpine maleate (MK-801; $0.25 \mathrm{mg} / \mathrm{kg}$, i.p.) or saline, and in experiment 3 with the competitive antagonist 3-[( \pm -2carboxypiperazin-4-yl]-propyl-1-phosphonic acid (CPP; 1.0 $\mathrm{mg} / \mathrm{kg}$, i.p.) or saline. In experiment 1 , behavior was assessed 3 and $8 \mathrm{~d}$ after lesioning before daily drug treatment; on days 9 and 10, basal extracellular DA and metabolites were measured in both striata using microdialysis. In experiments 2 and 3 , behavior was assessed on days 3 and 15 and microdialysis on days 16 and 17, 8-9 d post-termination of drug treatments. On day 3 , all animals turned ipsilateral to the lesion. On days 8 or 15 , saline-treated animals showed no behavioral asymmetries, whereas MK-801- and CPP-treated animals turned ipsilaterally. In antagonist-treated animals, basal levels of extracellular DA were lower on the lesioned side whether measured 9-10 or 16-17 d after lesioning, whereas in saline-treated animals DA levels on the two sides did not differ. These results suggest that glutamate plays a role in the development of compensatory changes in the DA neurons that accompany behavioral recovery from partial lesions of nigrostriatal DA system.

Key words: substantia nigra; 6-OHDA lesions; glutamate; behavioral recovery; striatal dopamine; microdialysis; NMDA antagonists; MK-801; CPP
Behavioral recovery after partial unilateral destruction of the nigrostriatal pathway is accompanied by normalization of extracellular dopamine (DA) in the striatum as measured by in vivo microdialysis (Robinson and Whishaw, 1988; Castañeda et al., 1990). This normalization takes place relatively gradually and appears to correspond with the time course of behavioral recovery (Robinson et al., 1994). Robinson et al. have shown that levels of extracellular DA in the striatum on the side of the lesioned substantia nigra are low $4 \mathrm{~d}$ after the lesions, when animals circle ipsilaterally, but recover to levels equal to those on the intact side in tests made 3-4 weeks later when behavioral deficits have recovered. The fact that basal levels of extracellular DA in striatum recover to normal levels (Abercrombie et al., 1990; Castañeda et al., 1990) when up to $85 \%$ of the neurons are destroyed suggests compensatory changes in the functioning of the remaining DA neurons. These may include both increased release of DA per impulse in remaining terminals as well as reduced uptake sites in the area (Snyder et al., 1990; Zigmond et al., 1992). One mechanism that might be responsible for the development of compensatory changes in the remaining DA neurons is increased glutamatergic tone in the substantia nigra after partial lesions of

Received Jan. 31, 1996; revised May 16, 1996; accepted May 30, 1996.

This research was funded by grants to J.S. from the Medical Research Council of Canada and from the Fonds pour la Formation de Chercheurs et l'Aide à la Recherche, Québec. A.E. was supported by a grant from Consiglio Nazionale delle Ricerche, Italy.

Correspondence should be addressed to Dr. Jane Stewart, Center for Studies in Behavioral Neurobiology, Department of Psychology, Concordia University, 1455 de Maisonneuve Boulevard West, Montréal, Québec, Canada H3G 1M8.

Copyright (C) 1996 Society for Neuroscience $0270-6474 / 96 / 165216-09 \$ 05.00 / 0$ the DA neurons. The substantia nigra is innervated by excitatory, presumably glutamatergic, inputs from the pedunculopontine nucleus, subthalamus (Smith and Grace, 1992), and cerebral cortex (Carter, 1982; Kornhuber et al., 1984), and it has been postulated that increased glutamatergic input to the substantia nigra may arise from lesions of the nigra DA cells (Albin et al., 1989; Greenamyre and O'Brien, 1991). Both AMPA and NMDA receptors have been shown in the substantia nigra and have been implicated in the regulation of DA cell firing. NMDA receptor stimulation has been shown to initiate burst firing (Overton and Clark, 1992) and to stimulate the release of DA from proximal and distal dendrites of DA cells in the substantia nigra (Gauchy et al., 1994), perhaps in the absence of cell firing. We speculated, therefore, that glutamatergic activity might contribute to changes in the nigrostriatal DA system that occur in the period immediately postlesion and that accompany behavioral recovery. To test this idea, three experiments were conducted in which the NMDA receptor antagonist MK-801 or CPP was given daily to animals on the first $8 \mathrm{~d}$ after partial unilateral 6-OHDA lesions in the substantia nigra. Behavioral recovery was assessed at different time points after the lesions and after termination of the daily treatments. Microdialysis was used to study the normalization of basal extracellular DA levels in the striatum.

\section{MATERIALS AND METHODS}

\section{Subjects}

Subjects were male Wistar rats weighing 350-380 gm at the beginning of each experiment. The rats were housed individually in plastic shoe box cages with tap water and standard rat chow available ad libitum. The light/dark cycle was reversed (lights off between 8:00 A.M. and 8:00 
P.M.), and testing was conducted during the dark phase of the cycle (from 8:00 A.M.).

\section{Drugs}

6-Hydroxydopamine hydrobromide with ascorbic acid (6-OHDA), dizocilpine maleate (MK-801), and 3-[( \pm )-2-carboxypiperazin-4-yl]-propyl-1phosphonic acid (CPP) were obtained from RBI Biochemicals; desmethylimipramine and pargyline were obtained from ICN Pharmaceuticals Canada.

\section{Surgery}

Animals were injected with desmethylimipramine $(15 \mathrm{mg} / \mathrm{kg}$, i.p. in 1.0 $\mathrm{ml} / \mathrm{kg}$ saline) $30 \mathrm{~min}$ before lesioning. They were anesthetized with sodium pentobarbital (Somnatol, SKF; $30 \mathrm{mg} / \mathrm{kg}$, i.p.) and injected with atropine sulfate $(0.5 \mathrm{mg} / \mathrm{ml}, 0.1 \mathrm{ml} / \mathrm{rat}$, s.c. $)$ and pargyline $(40 \mathrm{mg} / \mathrm{kg}$, s.c. in $1.0 \mathrm{ml} / \mathrm{kg}$ saline). Using a stereotaxic instrument set to obtain a flat skull, 6-OHDA (8 $\mu \mathrm{g} / 4 \mu \mathrm{l}$ saline) was injected unilaterally into the substantia nigra (anterior-posterior -5.4 , lateral 2.0, dorsal-ventral -9.3 from the skull surface) at a rate of $1 \mu \mathrm{l} / 5 \mathrm{~min}$ using a Hamilton microsyringe; the injector was removed $5 \mathrm{~min}$ after the end of the infusion.

With the stereotaxic arms angled $10^{\circ}$ from the vertical plane, 22 gauge stainless steel guide cannulae were implanted bilaterally into the striatum using the skull surface coordinates anterior-posterior +1.2 , lateral 3.0, and dorsal-ventral -3.4 . The cannulae were anchored to the skull with stainless steel screws and secured to the surface with dental cement. All animals were injected with penicillin $\mathrm{G}(300,000 \mathrm{IU}, 0.2 \mathrm{ml} / \mathrm{rat})$ after surgery.

\section{Behavioral tests}

To increase the probability of sustained behavioral activation without having to treat animals with a stimulant drug, one set of tests was conducted in the home cage at the beginning of the dark cycle when animals are active, and another set was conducted after animals were moved to a novel environment.

Locomotion and turning in home cage. Locomotor activity was measured for $10 \mathrm{~min}$ at the start of the dark phase of the cycle (8:00 A.M.) in the plastic shoe box home cages. A video camera and a videocassette recorder were used to record the behavior. Tapes were scored for the number of $360^{\circ}$ turns ipsilateral or contralateral to the lesion in $10 \mathrm{~min}$. The time spent drinking with one or the other side of the face toward the drinking tube was noted.

Water was available ad libitum, whereas access to food was interrupted during the observation.

Turning and wall facing in the novel environment. After the home cage observation, the behavior was monitored in a novel environment using a video image analyzing system (Chromotrack System, Poly-track model, San Diego Instruments). Four boxes $(58 \times 58 \times 48 \mathrm{~cm})$ built of wood, painted flat black, and open at the top were used. The video camera was connected to a computer located in a separate room. Using a combination of the software program provided and a record of the video image, behavior was scored for the number of $360^{\circ}$ turns ipsilateral and contralateral to the lesion and the time during which the vibrissae or the body of the moving animal was in contact with the wall of the open field (wall facing) (Steiner et al., 1988). Recording started $10 \mathrm{sec}$ after the rat was placed in the center of the field and lasted $5 \mathrm{~min}$.

\section{Microdialysis}

Microdialysis was conducted in four hexagonal testing chambers $(42 \times$ $39 \times 33.5 \mathrm{~cm}$ ) built from Plexiglas with wooden ceilings and stainless steel rod floors. Dark curtains were drawn around each chamber, and lighting was provided on a reversed cycle by overhead light bulbs $(15 \mathrm{~W})$. The dialysis probe consisted of a $3.5 \mathrm{~mm}$ length of semipermeable dialysis membrane (Spectra/Por; $240 \mu \mathrm{m}$ outer diameter, 13,000 molecular weight cutoff) closed at one end and attached at the other to a $19 \mathrm{~mm}$ length of 26 gauge stainless steel tubing. A $40-50 \mathrm{~cm}$ length of PE-20 tubing connected the other end of the stainless steel shaft to an infusion swivel stationed above the testing chamber, which was connected via PE-20 tubing to a variable-speed infusion pump. A small-diameter, fused silica tube extended internally through the probe with one end resting 0.5 $\mathrm{mm}$ from the tip of the probe and the other end exiting the PE tubing 35 $\mathrm{cm}$ below the infusion swivel. The probes were secured by brass collars that screwed onto the guide cannulae, and the external length of PE-20 tubing was protected from damage by steel spring casings. The probes were designed so that the entire length of semipermeable membrane extended below the guide cannula tip.

The probes were inserted the day before the beginning of microdialysis testing. To prevent occlusion, artificial CSF $\left(145 \mathrm{mM} \mathrm{Na}^{+}, 2.7 \mathrm{mM} \mathrm{K}^{+}\right.$, $1.22 \mathrm{mM} \mathrm{Ca}^{2+}, 1.0 \mathrm{~mm} \mathrm{Mg}{ }^{2+}, 150 \mathrm{mM} \mathrm{Cl}^{-}, 0.2 \mathrm{~mm}$ ascorbate, $2 \mathrm{mM}$ $\mathrm{Na}_{2} \mathrm{HPO}_{4}, \mathrm{pH}, 7.4+0.1$ ) was perfused overnight at a rate of $0.06 \mu \mathrm{l} / \mathrm{min}$.

Dialysate sampling and activity monitoring began the next morning. Half of the animals from each treatment condition were dialyzed on the lesioned side on the first day of dialysis and on the intact side on the second day of dialysis; for the other animals, the conditions were reversed. The dialysate flow rate was increased to $0.6 \mu \mathrm{l} / \mathrm{min}$, and baseline dialysate samples $(\sim 12 \mu \mathrm{l} / \mathrm{sample})$ were collected every $20 \mathrm{~min}$. A $10 \mu \mathrm{l}$ volume of dialysate was extracted from each sample and immediately analyzed using one of two similar high-performance liquid chromatography systems with electrochemical detection (HPLC-EC). The samples were loaded onto reverse-phase columns $(15 \times 0.46 \mathrm{~cm}$; SpherisorbODS2, $5 \mu \mathrm{m}$; Chromatography Sciences) through manual injection ports (Reodyn 7125; $20 \mu 1$ loop); reduction and oxidation currents for DA and its metabolites dihydroxyphenylacetic acid (DOPAC) and homovanillic acid (HVA) were measured with dual-channel ESA coulometric detectors (Coulochem 5100, with a model 5021 conditioning cell and a model 5011 analytical cell). The currents for DA were measured independent of those for DOPAC and HVA using separate channels of the Coulochem detectors. The mobile phases ( $25 \%$ methanol, 0.076 m SDS, 0.1 м EDTA, $0.058 \mathrm{M} \mathrm{NaPO}_{4}, 0.27 \mathrm{M}$ citric acid, $\mathrm{pH}=4.0$ ) were circulated through each closed system at a flow rate of $1.0 \mathrm{ml} / \mathrm{min}$ by Waters 510 HPLC pumps. The peaks obtained for DA, DOPAC, and HVA were integrated and quantified by EZChrom Chromatography Data System (Scientific Products \& Equipment). Dialysate samples from individual rats always were analyzed with the same HPLC-EC system, and the assignment of animals to each system was counterbalanced across all treatment groups. Food was removed from the chambers before sampling, but a water drinking tube was available.

\section{Postmortem tissue analysis}

Eleven days (experiment 1) and 18 days (experiments 2 and 3 ) after the 6-OHDA lesions were made, the animals were killed by decapitation and the brains were removed, placed in isopentane and instantly frozen on dry ice. The next day the brains were placed in a chilled cutting block, and 300 $\mu \mathrm{m}$ brain slices were obtained. The slices were immediately examined, and the location of the track formed by the probes was determined. One millimeter diameter punches were taken from the area immediately surrounding the probes.

The mobile phase was adjusted to allow for the separation and quantification of DA, DOPAC, and HVA in a single run. The brains from each set of drug-treated and saline-treated animals were analyzed in a single session. The tissue was frozen in $100 \mu \mathrm{l}$ mobile phase, thawed, and then centrifuged at 10,000 rpm for $15 \mathrm{~min}$. The supernatant was analyzed for amine content using HPLC-EC. Pellets were used for protein analysis.

The concentrations were estimated from peak height by comparison with injections of known amounts of pure standards (Sigma). The response of the chromatographic system was linear between amine concentrations of 100 and $1000 \mathrm{pg} / 20 \mathrm{ml}$ injection $(r$ 's $\geq 0.98)$. Intra-assay variability was $<5 \%$. Values are expressed as gm/mg protein.

\section{Design and procedures}

Figure 1 outlines the timing of the treatments and experimental manipulations in experiments 1,2 , and 3 . The procedures used for each of the experiments was identical, with the exception of the difference in time of behavioral testing and microdialysis after the discontinuation of drug treatments. The three experiments were performed at different times, each with its own saline control group.

Experiment 1. In this experiment, to determine whether glutamate played a role in the recovery from partial 6-OHDA lesions of the substantia nigra, animals were treated with the NMDA antagonist MK801 or with saline for $8 \mathrm{~d}$ after the lesion and were tested on the day after the last injection. Animals were injected daily at 10:00 A.M. on days 1-8 with either $0.25 \mathrm{mg} / \mathrm{kg} \mathrm{MK}-801(n=6)$ or saline $(n=5)$. On days 3 and 8 , behavioral observations were made in both environments before the drug treatments, beginning about 8:00 A.M. The animals were moved to the microdialysis chambers after testing on day 8 . The probes were inserted and perfused overnight at a rate of $<0.05 \mathrm{ml} / \mathrm{min}$. Dialysate sampling began on the morning of day 9 when half of the animals from each treatment condition were dialyzed on either the lesioned or the intact side. That evening, a probe was inserted into the other striata, and 


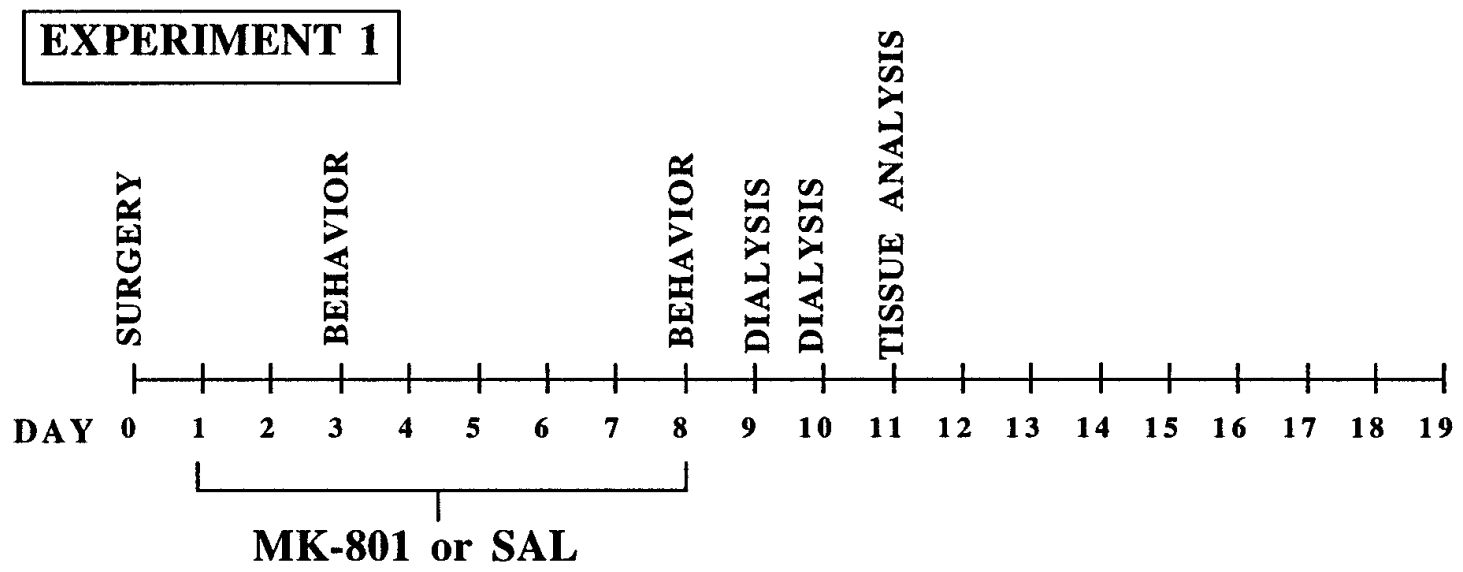

\section{EXPERIMENTS 2 and 3}

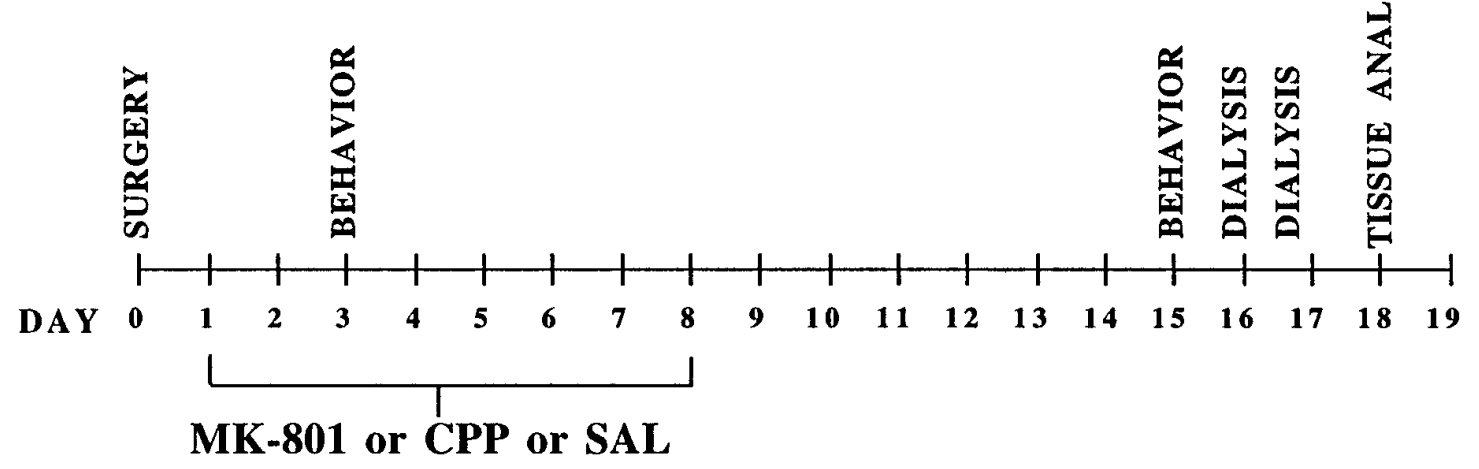

Figure 1. Outline of timing of treatments and experimental manipulations in experiments 1, 2, and 3.

on day 10 dialysate sampling began in the morning. The next day the animals were killed, and the brains were prepared for tissue analysis.

Experiment 2. In this experiment, to determine whether the effects of MK-801 given in the $8 \mathrm{~d}$ immediately postlesion were long-lasting, animals were injected daily from day $1-8$ but were not tested until after an additional $8 \mathrm{~d}$, during which no injections were given. Two groups of animals were injected daily at 10:00 A.M. on days $1-8$ with either 0.25 $\mathrm{mg} / \mathrm{kg}$ MK-801 $(n=6)$ or saline $(n=5)$. No injections were given on days 9-15. Beginning at 8:00 A.M. on days 3 and 15, behavioral observations were made in both environments. On day 15, animals from all conditions were moved to the microdialysis chambers; the probes were inserted and perfused overnight at a rate of $<0.05 \mathrm{ml} / \mathrm{min}$. Dialysate sampling began on the morning of day 16 when half of the animals from each treatment condition were dialyzed on either the lesioned or the intact side. That evening, a probe was inserted into the other striata, and on day 17 dialysate sampling began in the morning. The next day the animals were killed, and the brains were prepared for tissue analysis.

Experiment 3. In this experiment, to determine whether the effects seen after MK-801 arose from some unique property of that drug, animals were injected for $8 \mathrm{~d}$ after the lesions with the competitive NMDA receptor antagonist $\mathrm{CPP}$ and were tested after an $8 \mathrm{~d}$ drug-free period. The experiment was conducted in a manner identical to that of experiment 2 , except that animals were injected with either $1.0 \mathrm{mg} / \mathrm{kg} \mathrm{CPP}(n=$ $4)$ or saline $(n=4)$.

Finally, to test the possibility that the injection of an NMDA antagonist on the day immediately after the 6-OHDA lesioning might be interfering with behavioral recovery and normalization of basal levels of DA by potentiating the acute effects of the neurotoxin, an additional group of animals $(n=5)$ was given a single injection of $0.25 \mathrm{mg} / \mathrm{kg} \mathrm{MK}-801$ on day 1 postlesion. With the exception that the animals were given only one injection of MK-801, the animals were treated and tested as in experiments 2 and 3.

\section{RESULTS}

\section{Postmortem tissue analysis}

The mean \pm SEM DA depletions and absolute tissue levels of DA for animals in experiments 1,2 , and 3 are shown in Table 1. Although there is some variation between experiments in the absolute measures of DA in lesioned and intact sides of the brain, in all animals included in these studies, DA depletion on the lesioned side of individual animals ranged from 65 to $89 \%$ of that on the intact side. It is important to note that each experiment and its tissue analyses were performed at different times, and each HPLC run included a saline control and a drug treatment group. All the rats included in these experiments had probes correctly located in the striatum on both sides of the brain.

\section{Experiment 1: MK-801 days 1-8; test days 3, 8, 9, and 10}

In vivo microdialysis. Basal levels of DA, DOPAC, and HVA from the intact and lesioned striata of MK-801- and saline-treated animals tested 24 and $48 \mathrm{hr}$ after termination of injections are shown in Figure 2. Animals injected daily with MK-801 had significantly lower basal levels of DA in the striatum on the lesioned side than on the intact side, whereas in saline-treated animals there was no difference between the basal levels of DA on the lesioned and the intact side. In the case of HVA, levels were lower on the lesioned side in MK-801-treated animals; this is reflected in a significant effect of Treatment and a Treatment $\times$ Side interaction. The Treatment $\times$ Side interaction for DOPAC 


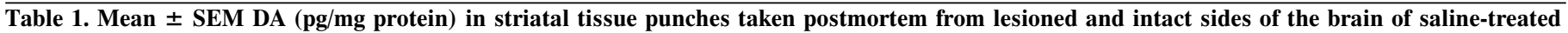
and antagonist-treated groups in each of the experiments

\begin{tabular}{|c|c|c|c|c|c|c|}
\hline \multirow[b]{2}{*}{ Experiment } & \multicolumn{3}{|c|}{ Saline-treated groups } & \multicolumn{3}{|c|}{ Antagonist-treated groups } \\
\hline & Intact & Lesion & $\%$ depletion & Intact & Lesion & $\%$ depletion \\
\hline 1 MK-801 & $139.2 \pm 7.0$ & $33.1 \pm 4.5$ & $76.5 \pm 2.2$ & $146.4 \pm 5.2$ & $34.4 \pm 2.6$ & $76.5 \pm 1.4$ \\
\hline 2 MK-801 & $84.9 \pm 6.9$ & $24.9 \pm 1.2$ & $70.2 \pm 2.2$ & $103.8 \pm 3.4$ & $22.52 \pm 2.4$ & $78.3 \pm 3.0$ \\
\hline $3 \mathrm{CPP}$ & $252.8 \pm 14.5$ & $39.3 \pm 5.9$ & $84.2 \pm 2.7$ & $196.7 \pm 28.7$ & $33.7 \pm 2.6$ & $81.4 \pm 3.7$ \\
\hline
\end{tabular}

was not significant. See legend of Figure 2 for results of statistical analyses.

Behavior. Home cage: as shown in Figure $3 A$, on day 3 both the MK-801- and saline-treated animals made a greater number of $360^{\circ}$ turns toward the lesioned side (Ipsi). By day 8, although all animals displayed an increase in total number of turns, salinetreated animals turned equally in both directions. MK-801-treated animals, however, continued to turn preferentially toward the lesioned side.

New environment: similar results were found for turning in the novel environment. As shown in Figure $3 B$, on day 3 animals in both treatment conditions turned predominantly toward the lesion side. By day 8, again saline-treated animals showed no preferential turning, whereas the MK-801-treated animals continued to turn more frequently toward the lesioned side. Figure $3 C$ shows the amount of time the vibrissae or the body of the moving animal was in contact with the wall of the open field. On day 3 , regardless of treatment condition, animals spent more time with the lesioned side toward the wall. By day 8, saline-treated animals did not show preference for either side, whereas the MK-801treated animals continued to keep the lesioned side toward the wall. See legend of Figure 3 for results of statistical analyses.

\section{Experiment 2: MK-801 days 1-8; test days 3, 15, 16, and 17} In vivo microdialysis. The basal levels of striatal DA, DOPAC, and HVA in animals tested on days 16 and 17, 8 and $9 \mathrm{~d}$ after the last of the daily injections, are shown in Figure 4. In saline-treated animals, basal levels of DA were the same in the two striata. In MK-801-treated animals, although DA levels on the intact side did not differ from those of saline-treated animals, levels on the lesioned side were significantly lower. See legend of Figure 4 for results of statistical analyses.

Behavior. Figure $5 A-C$ shows the behavior of animals tested on day 3 and again on day 15, $7 \mathrm{~d}$ after termination of MK-801 injections. The results for turning in the home cage, turning in the new environment, and wall facing were virtually identical to those seen in experiment 1 . MK-801-treated animals showed preference for turning toward the lesioned side (Ipsi) and for keeping the body on the side of the lesion toward the wall on both days 3 and 15 , whereas saline-treated animals showed no preference by day 15. These findings are reflected in the significant effects of Side on day 3 and significant interactions between Treatment $\times$ Side on day 15. See legend of Figure 5 for results of statistical analyses.

Experiment 3: CPP days 1-8; test days 3, 15, 16, and 17 In vivo microdialysis. Effects similar to those seen in MK-801treated animals in experiment 2 were found in this experiment in CPP-treated animals tested 8 and $9 \mathrm{~d}$ after the termination of the drug injections. Figure 6 shows that CPP-treated animals had low basal levels of DA on the lesioned side compared with the intact side. Levels in saline-treated animals were the same in both striata and did not differ from those on the intact side of CPP-treated animals. These effects are reflected in significant Treatment and Side effects and a Treatment $\times$ Side interaction. In CPP-treated animals, levels of HVA were lower on the lesioned side; a similar pattern was evident for DOPAC, but the effect was not significant. See legend of Figure 6 for statistical values.

Behavior. Figure $7 A-C$ shows the behavior of animals tested on day 3 and again on day 15, $7 \mathrm{~d}$ after the termination of CPP injections. The results in each of the behavioral tests mirrored those found after MK- 801 treatments. Animals in both the saline and CPP treatment conditions showed the effects of the lesion on day 3 , but by day 15 only those treated with CPP continued to show preferential ipsilateral turning and spent more time with the lesioned side of the body toward the wall of the open field (see legend of Fig. 7 for the results of the statistical analyses).

Finally, one group of animals was subjected to 6-OHDA lesions and treated the day after (day 1) with a single injection of MK-801 to control for the possibility that MK-801 or an NMDA antagonist could have aggravated the toxicity of 6-OHDA and thus interfered with recovery from the lesions. Three of the five animals in this group had DA depletions ranging from 82 to $89 \%$, and two had depletions of $35 \%$. As assessed in the turning tests, all animals showed behavioral deficits on day 3 and behavioral recovery on day 15 (see Fig. 8). In addition, these animals showed normalization of DA levels in the striatum on the lesioned side as assessed by microdialysis on days 16 and 17 . Mean DA levels on the lesioned and nonlesioned sides were $6.8 \pm 1.4$ and $8.1 \pm 1.4$, respectively; the ANOVA performed on these data showed no statistically significant effects of Side, Time, or Side $\times$ Time.

\section{DISCUSSION}

The purpose of these experiments was to determine whether glutamate plays a role in the changes that lead to the recovery of behavioral function and normalization of extracellular basal levels of DA in terminal regions after partial lesion of DA neurons in the substantia nigra. In experiment 1 , it was found that daily injections of the glutamate receptor antagonist MK-801, given for $8 \mathrm{~d}$ after partial 6-OHDA lesions of the nigrostriatal neurons, blocked the behavioral recovery evident in the saline-treated animals and resulted in low basal levels of striatal DA on the lesioned side of the brain. It was shown in experiment 2 that the effects of the MK- 801 given in the $8 \mathrm{~d}$ immediately postlesion were still evident in animals tested $<1$ week after the termination of drug treatment. The results of experiment 3 showed that the effects of MK-801 on biochemistry and behavior did not arise from some unique property of that drug, but could be obtained as well with the competitive NMDA antagonist CPP. The postmortem analysis of striatal tissue levels of DA revealed a dissociation between the percent DA depletion attributable to the 6-OHDA lesion and the extracellular levels of DA as measured by in vivo microdialysis. In each of the experiments, the percent DA depletion in the lesioned striatum (compared with the intact striatum) 

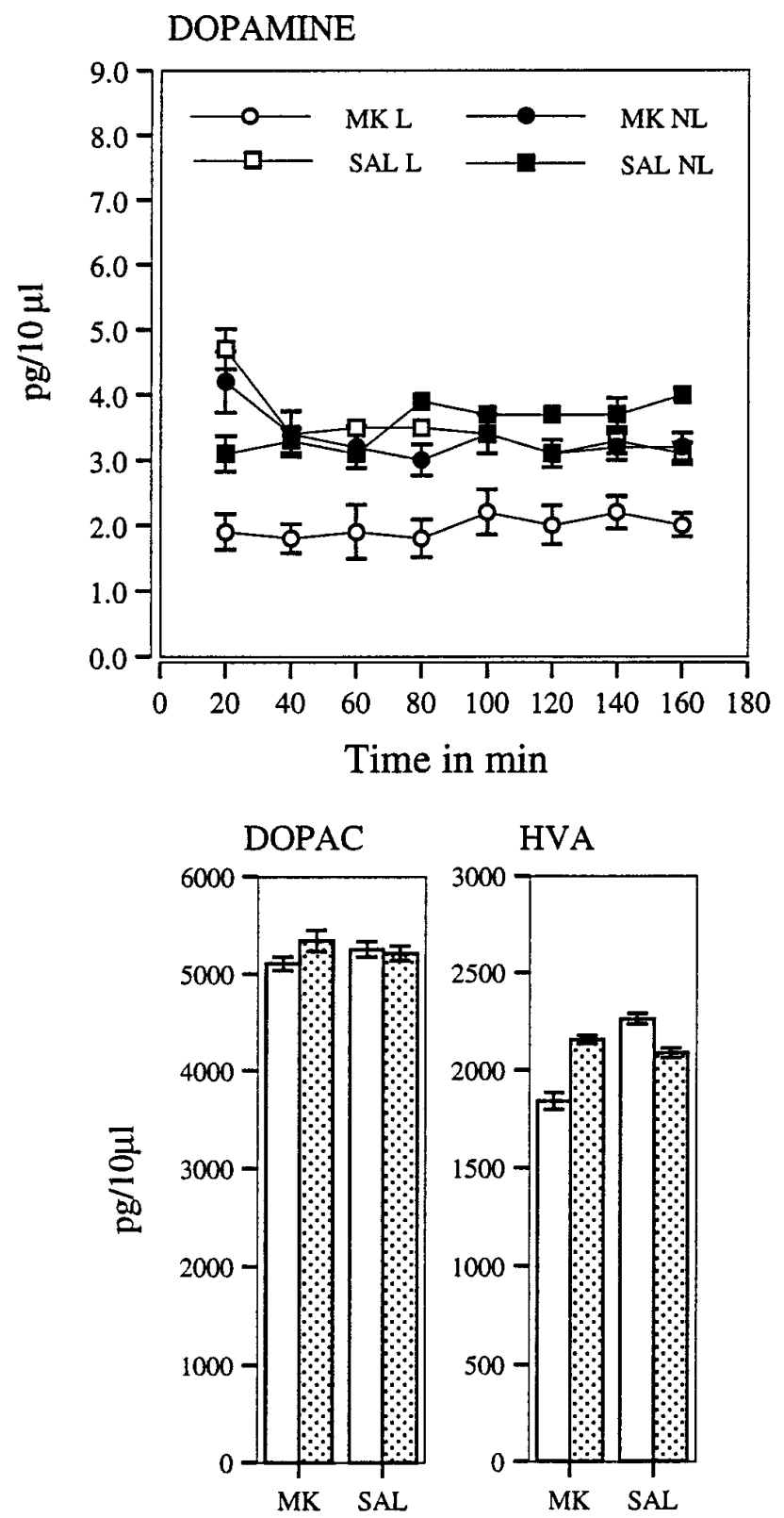

L $\quad$ NL

Figure 2. Microdialysis in experiment 1 (MK-801). Mean \pm SEM levels of dopamine in $\mathrm{pg} / 10 \mu \mathrm{l}$ dialysate samples taken at $20 \mathrm{~min}$ intervals on the lesioned and intact side of the striatum on days 9 and 10 after surgery in animals with unilateral 6-OHDA lesions in substantia nigra. Groups were treated with either $0.25 \mathrm{mg} / \mathrm{kg}$ MK- 801 or saline daily on days $1-8$ after surgery. The values for DOPAC and HVA represent the means of the eight samples taken over the same period. ANOVAs (Treatment $\times$ Side $\times$ Time): DA, Treatment $\left[F_{(1,63)}=14.6 ; p=0.004\right]$, Treatment $\times$ Side interaction $\left[F_{(1,63)}=12.7 ; p=0.006\right]$; HVA, Treatment $\left[F_{(1,63)}=15.3\right.$; $p=0.003]$, Treatment $\times$ Side interaction $\left[F_{(1,63)}=6.6 ; p=0.03\right]$. There was no significant Treatment $\times$ Side interactions for DOPAC.

was comparable in the antagonist-treated group as in the salinetreated group. In contrast to these findings, extracellular DA levels measured by microdialysis in vivo were not different in the two striata of the saline-treated groups, but were significantly lower on the lesioned side of the antagonist-treated groups. Thus, the differences between the saline and antagonist treatment

\section{A. Turning: Home Cage}

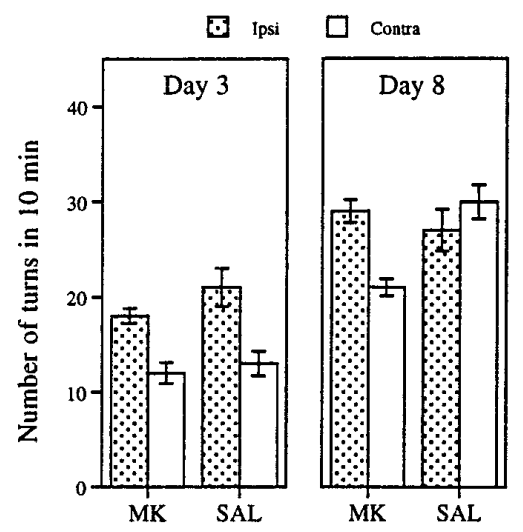

B. Turning: New Environment

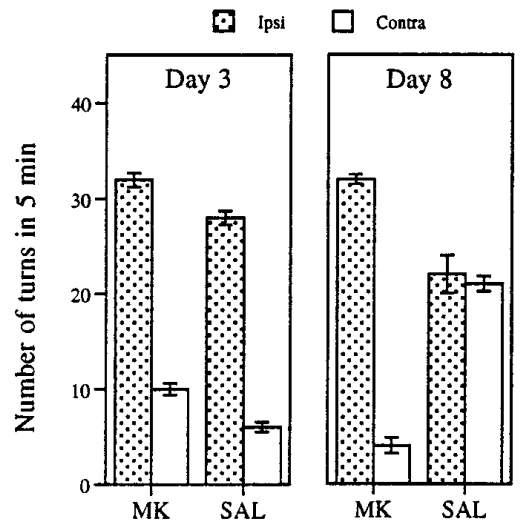

C. Wall Facing

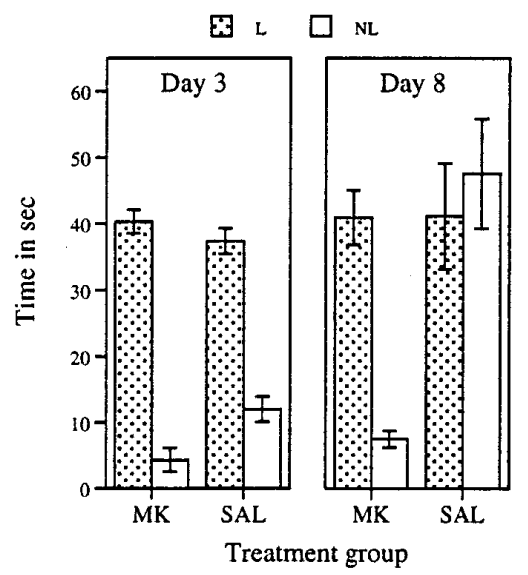

Figure 3. Behavior in experiment 1 (MK-801). Mean \pm SEM turning toward the side of the lesion (Ipsi) or away from the lesion (Contra) in animals tested on days 3 and 8 after surgery in the home cage $(A)$ and in a new environment $(B)$. $C$, Mean \pm SEM time the vibrissae or the body of the moving animal was in contact with the wall in the new environment. Groups were treated with either $0.25 \mathrm{mg} / \mathrm{kg}$ MK-801 or saline daily on days 1-8 after surgery. ANOVAs (Treatment $\times$ Side): $A$, day 3 , Side $\left[F_{(1,9)}=46.1 ; p=0.0002\right]$; day 8 , Side $\left[F_{(1,9)}=36.4 ; p=0.03\right]$ and Treatment $\times$ Side interaction $\left[F_{(1,9)}=170.0 ; p=0.0007\right] ; B$, day 3 , Treatment $\left[F_{(1,9)}=37.9 ; p=0.0003\right]$, Side $\left[F_{(1,9)}=565.0 ; p=0.0002\right]$; day 8 , Side $\left[F_{(1,9)}=191.5 ; p=0.0002\right]$ and Treatment $\times$ Side interaction $\left[F_{(1,9)}=180.7 ; p=0.0002\right] ; C$, day 3 , Side $\left[F_{(1,9)}=110.0 ; p=0.0001\right]$; day 8 , Side $\left[F_{(1,9)}=14.3 ; p=0.004\right]$ and Treatment $\times$ Side interaction $\left[F_{(1,9)}\right.$ $=31.1 ; p \stackrel{(1,9)}{=} 0.0003]$. 


\section{DOPAMINE}

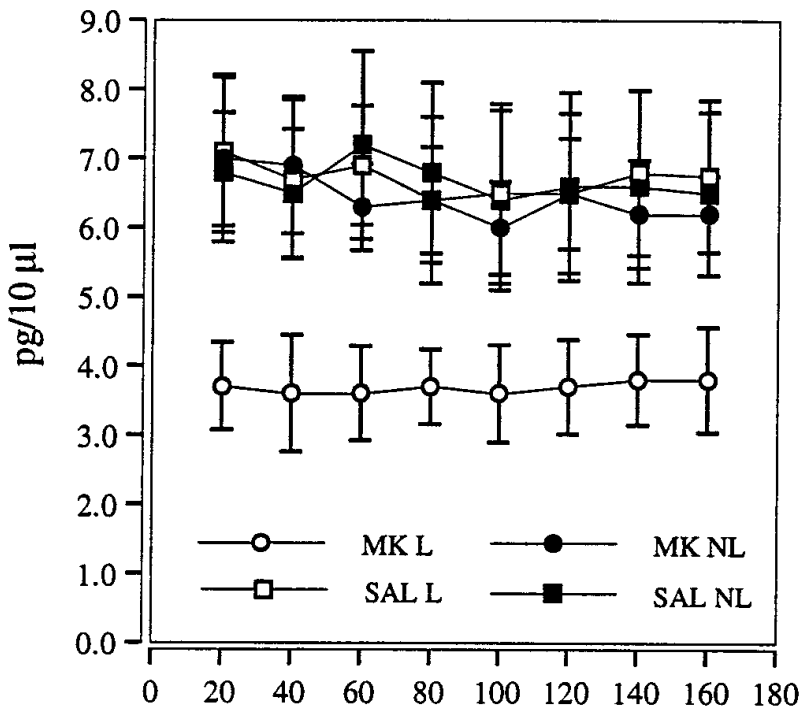

Time in $\min$
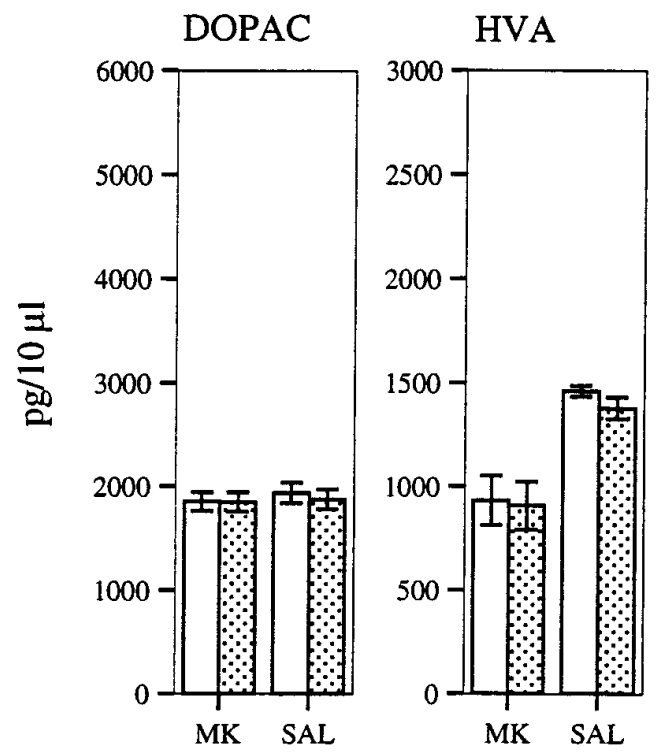

L $\quad$ NL

Figure 4. Microdialysis in experiment 2 (MK-801). Mean \pm SEM levels of dopamine in $\mathrm{pg} / 10 \mu \mathrm{l}$ dialysate samples taken at $20 \mathrm{~min}$ intervals on the lesioned and intact side of the striatum on days 16 and 17 after surgery in animals with unilateral 6-OHDA lesions in substantia nigra. Groups were treated with either $0.25 \mathrm{mg} / \mathrm{kg}$ MK-801 or saline daily on days $1-8$ after surgery. The values for DOPAC and HVA represent the means of the eight samples taken over the same period. ANOVA: Side Effect $\left[F_{(1,42)}=\right.$ $16.4 ; p=0.007]$ and the Treatment $\times$ Side interaction $\left[F_{(1,42)}=16.9 ; p=\right.$ $0.006]$. None of the analyses performed on metabolite data yielded significant effects or interactions.

groups found using microdialysis were not explained by different degrees of tissue depletion. Furthermore, it cannot be argued that treatment with the antagonist in the period immediately postlesion (day 1) added to or aggravated the neurotoxic effect of 6-OHDA. The animals in this condition showed behavioral recovery that matched that of saline-treated groups in the three experiments and showed normalization of basal DA levels in the striatum.

\section{A. Turning: Home Cage}

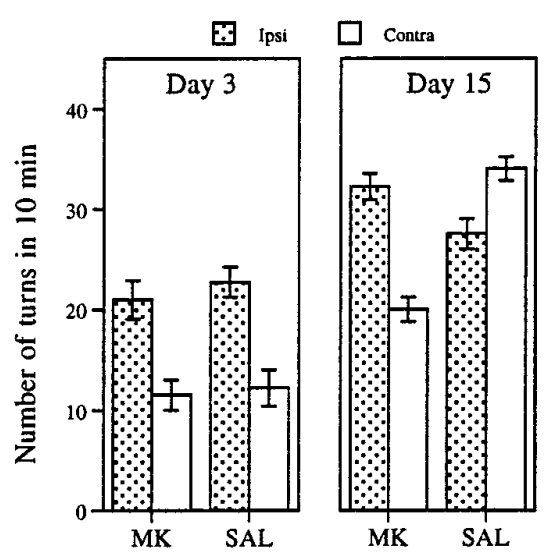

B. Turning: New Environment

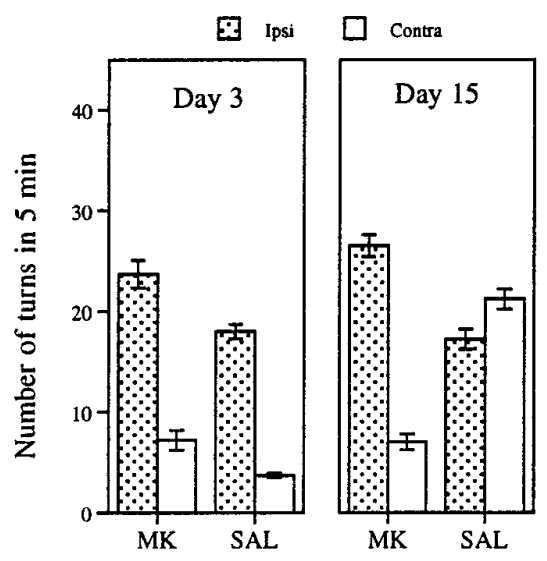

C. Wall Facing

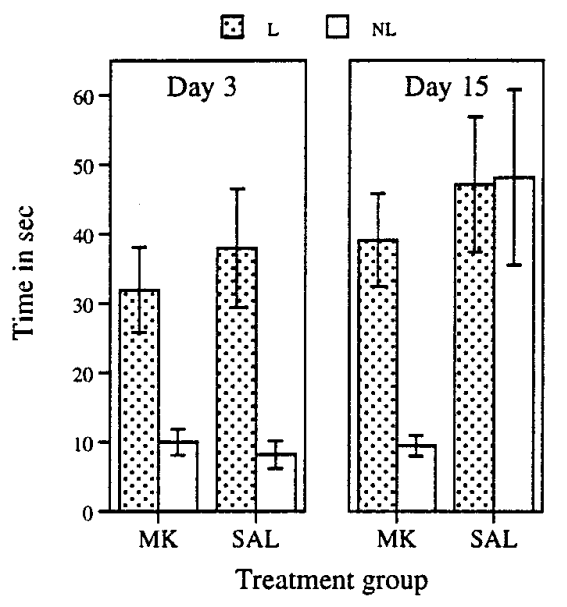

Figure 5. Behavior in experiment 2 (MK-801). Mean \pm SEM turning toward the side of the lesion (Ipsi) or away from the lesion (Contra) in animals tested on days 3 and 15 after surgery in the home cage $(A)$ and in a new environment $(B)$. $C$, Mean \pm SEM time the vibrissae or the body of the moving animal was in contact with the wall in the new environment. Groups were treated with either $0.25 \mathrm{mg} / \mathrm{kg}$ MK- 801 or saline daily on days $1-8$ after surgery. ANOVAs: $A$, day 3 , Side $\left[F_{(1,6)}=141.1 ; p=\right.$ $0.0002] ; B$, Side $\left[F_{(1,6)}=145.9 ; p=0.0002\right] ; C$, Side $\left[F_{(1,6)}=35.4 ; p=\right.$ $0.001]$. ANOVAs: $A$, day 15 , Treatment $\times$ Side $\left[F_{(1,6)}=92.2 ; p=0.0002\right]$; $B$, Treatment $\times$ Side $\left[F_{(1,6)}=602.4 ; p=0.0002\right] ; C$, Treatment $\times$ Side $\left[F_{(1,6)}=19.2 ; p=0.004\right]$. 


\section{DOPAMINE}
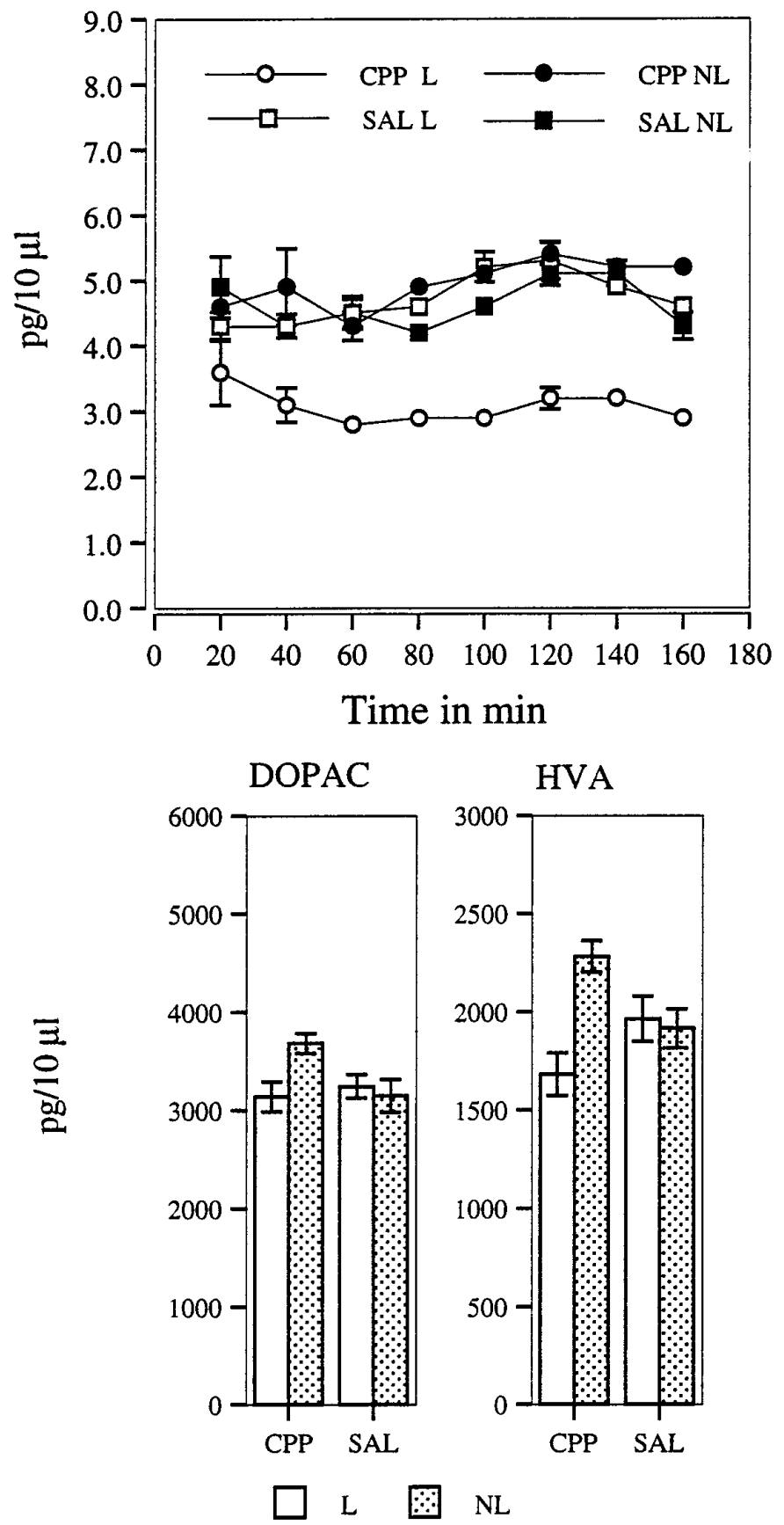

Figure 6. Microdialysis in experiment 3 (CPP). Mean \pm SEM levels of dopamine in $\mathrm{pg} / 10 \mu \mathrm{l}$ dialysate samples taken at $20 \mathrm{~min}$ intervals on the lesioned and intact side of the striatum on days 16 and 17 after surgery in animals with unilateral 6-OHDA lesions in substantia nigra. Groups were treated with either $1.0 \mathrm{mg} / \mathrm{kg} \mathrm{CPP}$ or saline daily on days $1-8$ after surgery. The values for DOPAC and HVA represent the means of the eight samples taken over the same period. ANOVAs: DA, Treatment $\left[F_{(1,42)}=\right.$ $45.1 ; p=0.0007]$, Side $\left[F_{(1,42)}=44.2 ; p=0.0007\right]$ and Treatment $\times$ Side interaction $\left[F_{(1,42)}=53.4 ; p=0.0005\right]$; HVA, Treatment $\times$ Side interaction $\left[F_{(1,42)}=13.9 ; p=0.009\right]$.

Blockade of NMDA glutamate receptors immediately postlesion appears to have had long-lasting consequences on the processes responsible for behavioral recovery and normalization of basal levels of DA in the striatum. MK-801- or CPP-treated
A. Turning: Home Cage

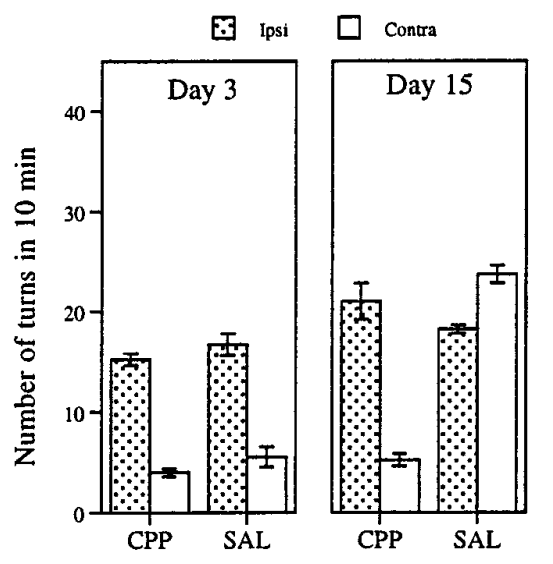

\section{B. Turning: New Environment}

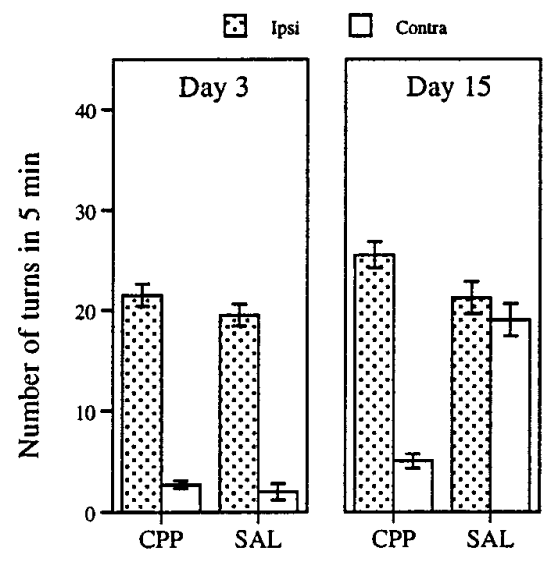

\section{Wall Facing}

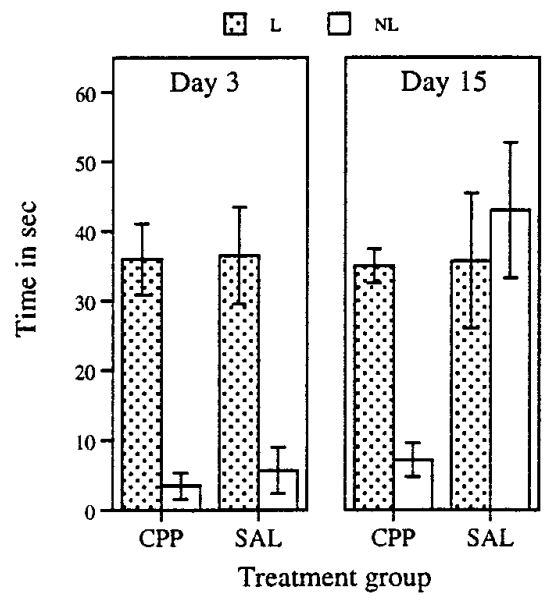

Figure 7. Behavior in experiment 3 (CPP). Mean \pm SEM turning toward the side of the lesion (Ipsi) or away from the lesion (Contra) in animals tested on days 3 and 15 after surgery in the home cage $(A)$ and in a new environment $(B)$. $C$, Mean \pm SEM time the vibrissae or the body of the moving animal was in contact with the wall in the new environment. Groups were treated with either $1.0 \mathrm{mg} / \mathrm{kg} \mathrm{CPP}$ or saline daily on days $1-8$ after surgery. ANOVAs: $A$, day 3 , Side $\left[F_{(1,6)}=\right.$ $113.5 ; p=0.0002] ; B$, Side $\left[F_{(1,6)}=304.7 ; p=0.0002\right] ; C$, Side $\left[F_{(1,6)}\right.$ $=54.5 ; p=0.0003]$. ANOVAs: $A$, day 15 , Treatment $\times$ Side $\left[F_{(1,6)}=\right.$ $123.8 ; p=0.0002] ; B$, Treatment $\times$ Side $\left[F_{(1,6)}=25.3 ; p=0.002\right] ; C$, Treatment $\times$ Side $\left[F_{(1,6)}=24.6 ; p=0.002\right]$. 


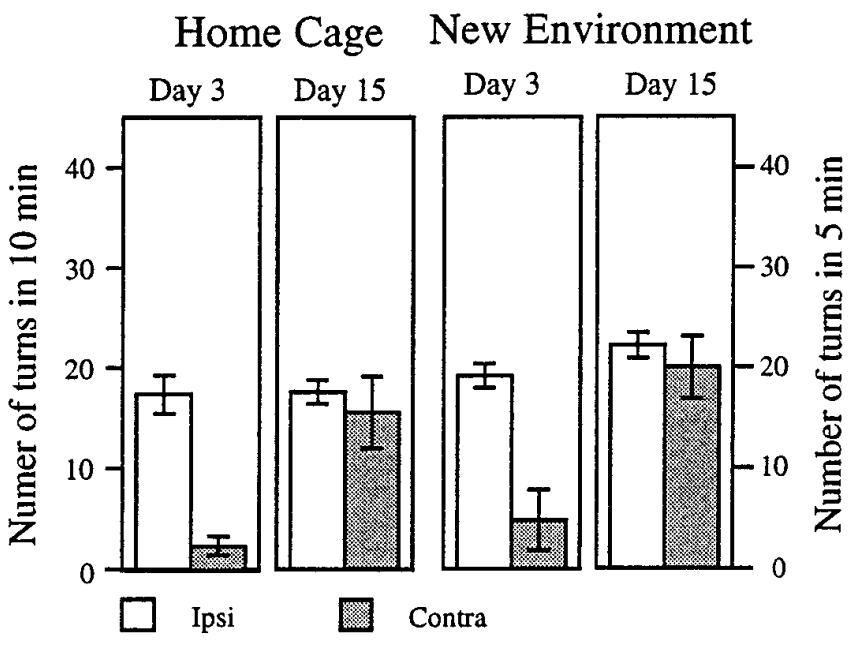

Figure 8. Behavior of animals treated with MK-801 on day 1 only. Mean \pm SEM turning toward the side of the lesion (Ipsi) or away from the lesion (Contra) in animals tested on days 3 and 15 after surgery in the home cage and in a new environment. All animals were given a single injection of $0.25 \mathrm{mg} / \mathrm{kg}$ MK-801 on the day after surgery, day 1 . ANOVAs for Side $\times$ Time of Test. Home Cage: Side $\left[F_{(1,4)}=8.9 ; p=0.04\right]$; Time $\left[F_{(1,4)}=16.23 ; p=0.01\right]$; Side $\times$ Time interaction $\left[F_{(1,4)}=10.90 ; p=\right.$ $0.03]$. New Environment: Side $\left[F_{(1,4)}=11.95 ; p=0.03\right]$; Time $\left[F_{(1,4)}=\right.$ $30.84 ; p=0.005]$; Side $\times$ Time interaction $\left[F_{(1,4)}=5.6 ; p=0.07\right]$.

animals showed no behavioral recovery and had low levels of extracellular DA in the lesioned striatum even though they were given an $8 \mathrm{~d}$ drug-free period after the treatment with the antagonists. These findings suggest that glutamate acts during a period with high potential for neural plasticity, the period immediately postlesion, to bring about enduring changes in DA functioning. Glutamate recently has been postulated to play a trophic role in cell survival and growth (Woolley and McEwen, 1994; Bambrick et al., 1995). Such a role may be particularly important during development and after brain injury.

How might glutamate promote behavioral recovery and normalization of extracellular DA in the striatum of animals sustaining up to $85 \%$ loss of DA neurons as measured by tissue levels of DA in the striatum? As discussed in the introductory remarks, it has been proposed that after partial lesions of the nigral DA neurons, there may be increased activity in glutamatergic neurons projecting to the substantia nigra that results from loss of inhibition by DA neurons (Albin et al., 1989; Greenamyre and O'Brien, 1991; Hollerman and Grace, 1992). Glutamate agonists have been shown to have effects on the activity of DA neurons (Overton and Clark, 1992) and on DA release in the terminal regions (Keefe et al., 1992; Taber et al., 1995; Karreman and Moghaddam, 1996). Recent studies have identified the cell bodies of midbrain neurons to be the primary site of action of glutamate on striatal DA release (Keefe et al., 1993; Taber et al., 1995; Karreman and Moghaddam, 1996). For example, it has been found that cortical activation of DA release in the striatum is mediated by glutamate indirectly via the dopamine cell bodies in the midbrain (Taber et al., 1995; Karreman and Moghaddam, 1996). We speculated that increased glutamatergic tone after partial lesions might contribute to plasticity within the nigrostriatal system by increasing the levels of extracellular DA in the somatodendritic region. Glutamate could increase extracellular DA in the somatodendritic region by stimulating release from dendrites (Gauchy et al., 1994) and in somatodendritic regions as well as terminal areas by promoting burst firing (Overton and Clark, 1992). Based on the results of the present experiments, we propose an action for glutamate on the remaining DA neurons that could have long-lasting effects and that might be responsible for enduring changes that are reflected in behavioral recovery and normalization of basal DA levels in the striatum after partial lesions within the nigrostriatal DA system.

The finding that DA neurons that survive partial 6-OHDA lesions of the substantia nigra come, in time, to produce and release enough DA to maintain normal basal levels of extracellular DA in the striatum (Robinson and Whishaw, 1988; Castañeda et al., 1990; Robinson et al., 1994), is reminiscent of two other phenomena involving long-term changes in DA functioning. One is found after chronic neuroleptic treatment when a large proportion of SN DA neurons are in a state of depolarization block, and when, in spite of this, basal levels of striatal DA are normal (Patterson and Schenk, 1991; Moghaddam and Bunney, 1993). Interestingly, this normalization is accompanied by increases in extracellular levels of glutamate in the striatum (Moghaddam and Bunney, 1993; Yamamoto and Cooperman, 1994). This latter finding, combined with the recently reported increases in immunoreactivity and mRNA levels for the NMDAR1 subunit in striatum in such animals (Fitzgerald et al., 1995), suggests that glutamate could act locally to maintain the basal levels of striatal DA. It may be, however, that the effects of glutamate are indirect, because it has been found that the basal levels of striatal DA in both neuroleptic-treated and saline-treated animals are impulsedependent (Moghaddam and Bunney, 1993). A second phenomenon that bears some similarity to the phenomenon of restoration of normal basal levels of striatal DA after partial lesions is that which occurs after repeated injections of amphetamine. Under these circumstances, two indications of increased dopaminergic activity are seen in striatal regions after termination of drug treatments; higher basal levels of DA metabolites (Robinson et al., 1988; Akimoto et al., 1990; Patrick et al., 1991; Vezina, 1993) and increased extracellular DA levels in response to amphetamine challenge (see Robinson and Becker, 1986; Kalivas and Stewart, 1991). Interestingly, these changes in extracellular DA measured in striatal regions by microdialysis (and in vitro tissue preparations) take time to develop, appearing several days to weeks after the termination of drug treatment (Kolta et al., 1985; Kalivas and Duffy, 1993; Paulson and Robinson, 1995). These long-lasting neuronal changes that accompany the enduring behavioral sensitization of the effects of amphetamine suggest a permanent reorganization within the system (Robinson and Becker, 1986). There is considerable evidence that the events that lead to amphetamine-induced sensitization of DA functioning are initiated by actions of amphetamine in the somatodendritic region of the midbrain DA neurons (Kalivas and Weber, 1988; Vezina and Stewart, 1990; Vezina, 1993). Interestingly, glutamate appears to be important in the development of sensitization to amphetamine and other stimulants. It has been found in several laboratories that animals coinjected with the glutamate receptor antagonist MK-801 do not develop sensitization to amphetamine (Karler et al., 1989, 1990; Wolf and Khansa, 1991; Stewart and Druhan, 1993; Wolf and Jeziorski, 1993; Wolf et al., 1994), and that NMDA antagonists injected directly into the cell body region of the midbrain DA neurons can block the development of sensitization (Kalivas and Alesdatter, 1993).

We hypothesize that in the case of partial 6-OHDA lesions, glutamate acts via NMDA receptor activation to stimulate release of DA from dendrites and perhaps to facilitate burst firing of DA neurons, thereby increasing extracellular DA in the cell body region 
of the DA neurons. Such increases in DA may be sufficient to lead to long-lasting reorganization within the somatodendritic region of the DA cells of the substantia nigra (Kalivas and Stewart, 1991; Kalivas, 1995), and thereby lead to long-lasting changes in intracellular events that control DA synthesis and availability in striatal terminal regions (Robinson and Becker, 1986; Vezina, 1993, 1996).

\section{REFERENCES}

Abercrombie ED, Bonatz AE, Zigmond MJ (1990) Effects of L-DOPA on extracellular dopamine in striatum of normal and 6-hydroxydopamine-treated rats. Brain Res 525:36-44.

Akimoto K, Hamamura T, Kazahaya Y, Akiyama K, Otsuki S (1990) Enhanced extracellular dopamine level may be the fundamental neuropharmacological basis of cross-behavioral sensitization between methamphetamine and cocaine-an in vivo dialysis study in freely moving rats. Brain Res 507:344-346.

Albin R, Young A, Penney J (1989) The functional anatomy of basal ganglia disorders. Trends Neurosci 12:366-375.

Bambrick L, Yarowsky P, Krueger B (1995) Glutamate as a hippocampal neuron survival factor: an inherited defect in the trisomy 16 mouse. Proc Natl Acad Sci USA 92:9692-9696.

Carter CJ (1982) Topographical distribution of possible glutamatergic pathways from the frontal cortex to the striatum and substantia nigra in rats. Neuropharmacol 21:379-383.

Castañeda E, Whishaw IQ, Robinson TE (1990) Changes in striatal dopamine neurotransmission assessed with microdialysis following recovery from a bilateral 6-OHDA lesion: variation as a function of lesion size. J Neurosci 10:1847-1854.

Fitzgerald LW, Deutch AY, Gasic G, Heinemann F, Nestler EJ (1995) Regulation of cortical and subcortical glutamate receptor subunit expression by antipsychotic drugs. J Neurosci 15:2453-2461.

Gauchy C, Desban M, Glowinski J, Kemel ML (1994) NMDA regulation of dopamine release from proximal and distal dendrites in the cat substantia nigra. Brain Res 635:249-256.

Greenamyre J, O'Brien C (1991) $N$-methyl-D-aspartate antagonists in the treatment of Parkinson's disease. Arch Neurol 48:977-981.

Hollerman J, Grace A (1992) Subthalamic nucleus cell firing in the 6-OHDA-treated rat: basal activity and response to haloperidol. Brain Res 590:291-299.

Kalivas PW (1995) Interactions between dopamine and excitatory amino acids in behavioral sensitization to psychostimulants. Drug Alcohol Depend 37:95-100.

Kalivas PW, Alesdatter JE (1993) Involvement of NMDA receptor stimulation in the VTA and amygdala in behavioral sensitization to cocaine. J Pharmacol Exp Ther 267:486-495.

Kalivas PW, Duffy P (1993) Time course of extracellular dopamine and behavioral sensitization to cocaine. I. Dopamine axon terminals. J Neurosci 13:266-275.

Kalivas PW, Stewart J (1991) Dopamine transmission in the initiation and expression of drug- and stress-induced sensitization of motor activity. Brain Res Rev 16:223-244.

Kalivas PW, Weber B (1988) Amphetamine injection into the A10 dopamine region sensitizes rats to peripheral amphetamine and cocaine. J Pharmacol Exp Ther 245:1095-1102.

Karler R, Calder LD, Chaudhry IA, Turkanis SA (1989) Blockade of "reverse tolerance" to cocaine and amphetamine by MK-801. Life Sci 45:599-606

Karler R, Chaudhry IA, Calder LD, Turkanis SA (1990) Amphetamine behavioral sensitization and the excitatory amino acids. Brain Res 537:76-82.

Karreman M, Moghaddam B (1996) The prefrontal cortex controls the basal release of DA in the medial striatum: an effect mediated by dopamine cell bodies. J Neurochem 66:589-598.

Keefe KA, Zigmond MJ, Abercrombie ED (1992) Extracellular dopamine in striatum influence nerve impulse activity in medial forebrain bundle and local glutamatergic input. Neuroscience 47:325-332.

Keefe K, Sved A, Zigmond M, Abercrombie E (1993) Stress-induced dopamine release in the neostriatum: evaluation of the role of action potentials in nigrostriatal dopamine neurons or local initiation by endogenous amino acids. J Neurochem 61:1943-1952.

Kolta MG, Shreve P, De Souza V, Uretsky NJ (1985) Time course of the development of the enhanced behavioral and biochemical responses to amphetamine after pretreatment with amphetamine. Neuropharmacology 24:823-829.
Kornhuber J, Kim J, Kornhuber M, Kornhuber H (1984) The corticonigral projection: reduced glutamate content in the substantia nigra following frontal cortex ablation in the rat. Brain Res 322:124-126.

Moghaddam B, Bunney B (1993) Depolarization inactivation of dopamine neurons: terminal release characteristics. Synapse 14:195-200.

Overton P, Clark D (1992) Iontophoretically administered drugs acting at the $N$-methyl-D-aspartate receptor modulate burst firing in A9 dopamine neurons in the rat. Synapse 10:131-140.

Patrick SL, Thompson TL, Walker JM, Patrick RL (1991) Concomitant sensitization of amphetamine-induced behavioral stimulation and in vivo dopamine release from rat caudate nucleus. Brain Res 538:343-346.

Patterson T, Schenk J (1991) Effects of acute and chronic systemic administration of some typical antipsychotic drugs on turnover of dopamine and potassium ion-induced release of dopamine in the striatum of the rat in vivo. Neuropharmacology 30:943-952.

Paulson PE, Robinson TE (1995) Amphetamine-induced time-dependent sensitization of dopamine neurotransmission in the dorsal and ventral striatum: a microdialysis study in behaving rats. Synapse 19:56-65.

Robinson TE, Becker JB (1986) Enduring changes in brain and behavior produced by chronic amphetamine administration: a review and evaluation of animal models of amphetamine psychosis. Brain Res Rev 396:157-198.

Robinson TE, Whishaw IQ (1988) Normalization of extracellular dopamine in striatum following recovery from a partial unilateral 6-OHDA lesion of the substantia nigra: a microdialysis study in freely moving rats. Brain Res 450:209-224.

Robinson TE, Jurson PA, Bennett JA, Bentgen KM (1988) Persistent sensitization of dopamine neurotransmission in ventral striatum nucleus accumbens produced by prior experience with +-amphetamine: a microdialysis study in freely moving rats. Brain Res 462:211-222.

Robinson TE, Mocsary Z, Camp DM, Whishaw IQ (1994) Time course of recovery of extracellular dopamine following partial damage to the nigrostriatal dopamine system. J Neurosci 14:2687-2696.

Smith I, Grace A (1992) Role of the subthalamic nucleus in the regulation of nigral dopamine neuron activity. Synapse 12:287-303.

Snyder G, Keller RWJ, Zigmond MJ (1990) Dopamine efflux from striatal slices after intracerebral 6-hydroxydopamine: evidence for compensatory hyperactivity of residual terminals. J Pharmacol Exp Ther 253:867-876.

Steiner H, Bonatz AE, Huston JP, Schwarting R (1988) Lateralizad wall-facing versus turning as measures of behavioral asymmetries and recovery function after injection of 6-hydroxydopamine into the substantia nigra. Exp Neurol 99:556-566.

Stewart J, Druhan JP (1993) Development of both conditioning and sensitization of the behavioral activating effects of amphetamine is blocked by the non-competitive NMDA receptor antagonist, MK-801. Psychopharmacology 110:125-132.

Taber M, Das S, Fibiger H (1995) Cortical regulation of subcortical dopamine release: mediation via the ventral tegmental area. J Neurochem 65:1407-1410.

Vezina P (1993) Amphetamine injected into the ventral tegmental area sensitizes the nucleus accumbens dopaminergic response to systemic amphetamine: an in vivo microdialysis study in the rat. Brain Res 605:332-337.

Vezina P (1996) D1 dopamine receptor activation is necessary for the induction of sensitization by amphetamine in the ventral tegmental area. J Neurosci 16:2411-2420.

Vezina P, Stewart J (1990) Amphetamine administered to the ventral tegmental area but not to the nucleus accumbens sensitizes rats to systemic morphine: lack of conditioned effects. Brain Res 516:99-106.

Wolf ME, Jeziorski M (1993) Coadministration of MK-801 with amphetamine, cocaine or morphine prevents rather than transiently masks the development of behavioral sensitization. Brain Res 613:291-294.

Wolf ME, Khansa MR (1991) Repeated administration of MK-801 produces sensitization to its own locomotor stimulant effects but blocks sensitization to amphetamine. Brain Res 562:164-168.

Wolf ME, White FJ, Hu X (1994) MK-801 prevents alterations in the mesoaccumbens dopamine system associated with behavioral sensitization to amphetamine. J Neurosci 14:1735-1745.

Woolley C, McEwen B (1994) Estradiol regulates hippocampal dendritic spine density via an $N$-methyl-D-aspartate receptor-dependent mechanism. J Neurosci 14:7680-7687.

Yamamoto B, Cooperman M (1994) Differential effects of chronic antipsychotic drug treatment on extracellular glutamate and dopamine concentrations. J Neurosci 14:4159-4166.

Zigmond MJ, Hastings TG, Abercrombie ED (1992) Neurochemical responses to 6-hydroxydopamine and L-DOPA therapy: implication for Parkinson's disease. Ann N Y Acad Sci 648:71-86. 